\title{
Systematic Studies on the Effect of Fluorine Atoms in Fluorinated Tolanes on Their Photophysical Properties
}

\author{
Masato Morita, Shigeyuki Yamada *(D) and Tsutomu Konno \\ Faculty of Molecular Chemistry and Engineering, Kyoto Institute of Technology, Matsugasaki, Sakyo-ku, \\ Kyoto 606-8585, Japan; kit.fusso.201602@gmail.com (M.M.); konno@kit.ac.jp (T.K.) \\ * Correspondence: syamada@kit.ac.jp; Tel.: +80-75-724-7517
}

Citation: Morita, M.; Yamada, S.;

Konno, T. Systematic Studies on the

Effect of Fluorine Atoms in

Fluorinated Tolanes on Their Photophysical Properties. Molecules 2021, 26, 2274. https://doi.org/ $10.3390 /$ molecules 26082274

Academic Editor: Viktor

O. Iaroshenko

Received: 17 March 2021

Accepted: 8 April 2021

Published: 14 April 2021

Publisher's Note: MDPI stays neutral with regard to jurisdictional claims in published maps and institutional affiliations.

\begin{abstract}
In this study, we synthesized a series of fluorinated and non-fluorinated tolanes, in which one or more fluorine atoms were systematically introduced into one aromatic ring of a tolane scaffold, and systematically evaluated their photophysical properties. All the tolanes with or without fluorine substituents were found to have poor photoluminescence (PL) in tetrahydrofuran (THF) solutions. On the other hand, in the crystalline state, non-fluorinated and fluorinated tolanes with one or four fluorine atoms were less emissive, whereas fluorinated tolanes with three or five fluorine atoms exhibited high PL efficiencies $\left(\phi_{\mathrm{PL}}\right)$ up to 0.51 . X-ray crystallographic analyses of the emissive fluorinated tolanes revealed that the position of the fluorine substituent played a key role in achieving a high $\phi_{\mathrm{PL}}$. Fluorine substituents at the ortho (2/6) and para (4) positions led to tight and rigid packing due to plural $\pi-\pi$ stacking and/or hydrogen bonding interactions, resulting in enhanced $\phi_{\mathrm{PL}}$ caused by the suppression of non-radiative deactivation. Additionally, fluorinated tolanes with three fluorine atoms exhibited notable aggregation-induced PL emission enhancement in THF/water mixed solvents. This demonstrates that the PL characteristics of small PL materials can be tuned depending on the usage requirements.
\end{abstract}

Keywords: aggregation-induced emission enhancement; fluorine; fluorescence; photoluminescence; tolane

\section{Introduction}

Tolanes, which consist of two benzene rings connected with alkyne moiety, have drawn enormous interest as promising small-sized functional molecules owing to their broad applications, such as two-photon absorbers [1-3], liquid crystals [4-6], light-activated DNA cleavers [7,8], and organic semiconductors [9]. Small-sized solid-state luminescent materials are also needed for practical applications in light-emitting diodes or lighting devices, whereas it is known that tolanes do not emit photoluminescence (PL) because they undergo excitation via the "dark" trans-bent $\pi \sigma^{*}$ excited states [10-14].

As a result of extensive photophysical investigations of tolane and the derivatives in recent years, significant advances have been achieved in developing tolane-based compounds that exhibit unique luminescence phenomena. Examples of such innovations include the tethering of two benzene rings of tolane, which induces the emission of phosphorescence in organic glass or solution states (Figure 1a) [15,16], crystallization or the formation of molecular aggregates of tolane derivatives (Figure 1b), which emit fluorescence, and enhancement of the fluorescence of tolanes by suppressing internal conversion from $\pi \pi^{*}$ to the "dark" trans-bent $\pi \sigma$ excited states $[17,18]$. Additionally, tolanes bearing fluoropyrrole groups exhibit dual-state fluorescence, emitted both in the solution and powder states (Figure 1c) [19].

Over the last couple of years, our group has explored the synthesis and properties of fluorinated PL molecules because fluorine atoms incorporated into organic structures play a crucial role in the formation of ordered molecular aggregates. The unique characteristics of fluorine atom that contribute to this effect include its (i) large electronegativity, 
higher than that of all the other elements; and (ii) small atomic size, second only to the size of the hydrogen atom, etc. $[20,21]$. Our extensive efforts have led to the successful development of fluorinated tolane-based PL molecules [22-24]. From our previous results, fluorinated tolanes were found to possess both crystallization-induced emission enhancement (CIEE) as well as aggregation-induced emission enhancement (AIEE) characteristics (Figure 1d) [23,24]. A deep investigation using X-ray crystallographic analyses has revealed that fluorinated tolane $\mathbf{B}$ in the crystalline state exhibits enhanced PL properties, while the non-fluorinated tolane A counterpart does not, owing to the tight and rigid molecular packing through several intermolecular hydrogen bonds, which are needed to suppress the non-radiative deactivation process.

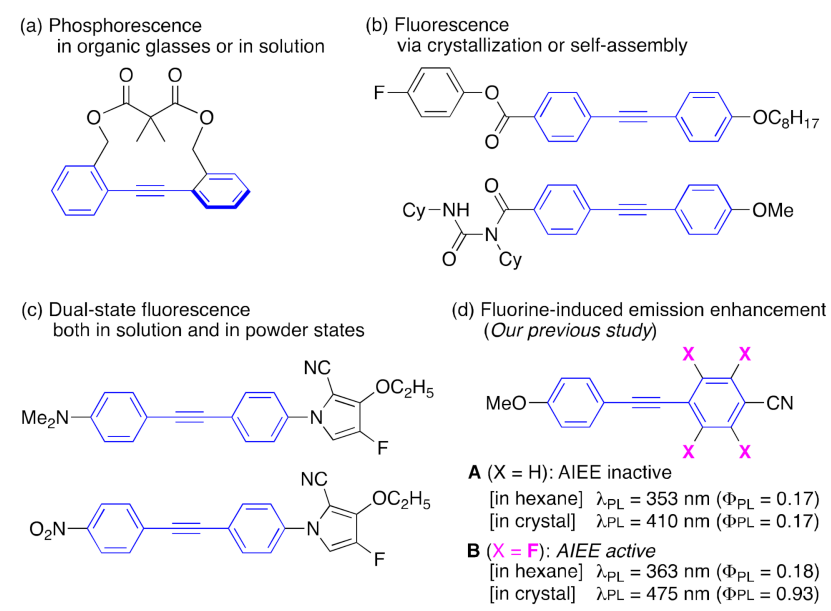

Figure 1. Tolane-based luminescent molecules reported in the literature: (a) twist tolanes showing phosphorescence in organic glasses or in solution, (b) donor- $\pi$-acceptor-type tolanes displaying fluorescence via crystallization or self-assembly, (c) tolanes exhibiting dual-state fluorescence, and (d) non-fluorinated or fluorinated tolanes-based fluorophores. Abbreviation: AIEE: aggregation-induced emission enhancement.

To further elucidate the effect of factors such as the number of fluorine atoms and positions of the fluorine substituents on the PL characteristics, we systematically synthesized tolane derivatives $\mathbf{0 F}-\mathbf{4 F}$ with a systematic arrangement of the number and position of fluorine substituents, as shown in Figure 2. In this paper, we demonstrate and discuss the photophysical behavior of $\mathbf{0 F}-\mathbf{4 F}$. In addition, the photophysical behavior and molecular aggregated structures in the crystalline state of $5 \mathrm{~F}$, which contains five fluorine atoms, are discussed and compared with other such materials in detail, although some photophysical behaviors of $5 \mathrm{~F}$ in solution and amorphous states have been reported previously [24].

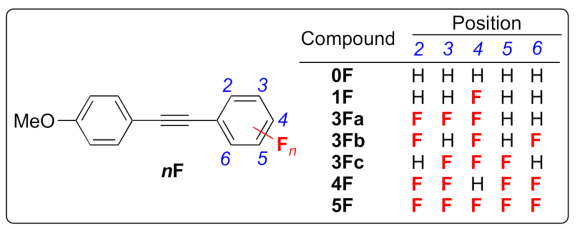

Figure 2. Molecular structures of the fluorinated tolanes used in this study.

\section{Results and Discussion}

Based on the synthesis protocol reported previously for $5 \mathrm{~F}$ [24], tolane $\mathbf{0 F}$ (without fluorine substituents) and $\mathbf{1 F}-\mathbf{4 F}$ (with fluorine substituents) were prepared via a $\operatorname{Pd}(0)$ catalyzed Sonogashira cross-coupling reaction using commercially available 4-ethynylanisole and various non-fluorinated or fluorinated aromatic halides. Yields in the range of 46-94\% were achieved (Figure S1). In order to assess the photophysical behavior of the compounds in the crystalline state, tolanes $\mathbf{0 F}-5 \mathbf{F}$ were crystallized through double purification by 
column chromatography, followed by recrystallization. Based on several spectroscopic studies, the tolane $\mathbf{0 F}-\mathbf{5} \mathbf{F}$ crystals were determined to be adequately pure to evaluate photophysical properties such as ultraviolet-visible light (UV-vis) absorption and PL behavior, both in dilute solutions and the crystalline state (Figures S2-S15).

To investigate the effect of fluorine substituents introduced into the tolane scaffold on the photophysical behavior, we initially attempted to measure UV-vis absorption and PL for dilute solution samples, which were prepared by dissolving tolane crystalline powder in tetrahydrofuran (THF) to achieve a $1.0 \times 10^{-5} \mathrm{~mol} \mathrm{~L}^{-1}$ concentration. The UV-vis and PL spectra obtained for these samples are shown in Figure 3 and Figures S16-S27, while the photophysical data are summarized in Table 1 and Table S1.

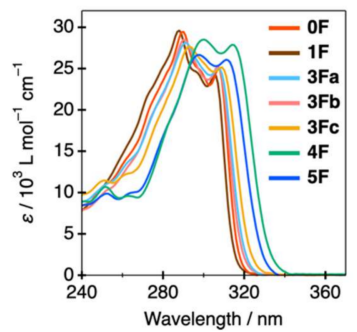

(a)

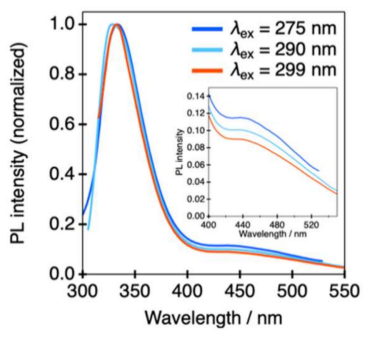

(c)

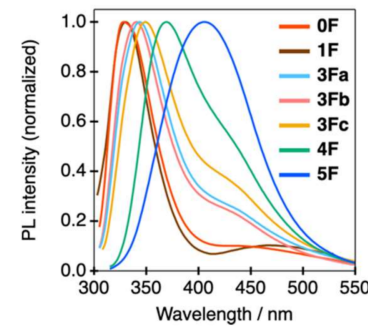

(b)

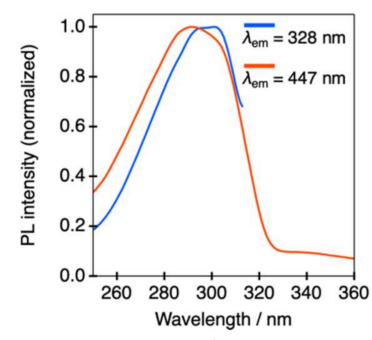

(d)

Figure 3. (a) UV-vis spectra of $\mathbf{0 F}-\mathbf{5 F}$; (b) photoluminescence (PL) spectra of $\mathbf{0 F}-5 \mathbf{F}$ excited at $\left(\lambda_{\mathrm{abs}}\right)$ $290 \mathrm{~nm}$ for $\mathbf{0 F}, 288 \mathrm{~nm}$ for $\mathbf{1 F}, 291 \mathrm{~nm}$ for 3Fa, $290 \mathrm{~nm}$ for 3Fb, $293 \mathrm{~nm}$ for 3Fc, $300 \mathrm{~nm}$ for 4F, and 297 $\mathrm{nm}$ for $5 \mathrm{~F}$; (c) PL spectra of $\mathbf{0 F}$ at various excitation wavelengths; and (d) excitation spectra of $\mathbf{0 F}$ at 328 and $447 \mathrm{~nm}$.

Table 1. Photophysical properties of tolanes $\mathbf{0 F}-\mathbf{5 F}$ in dilute THF solution (concentration: $1.0 \times 10^{-5} \mathrm{~mol} \mathrm{~L}^{-1}$ ).

\begin{tabular}{|c|c|c|c|c|c|c|c|c|c|}
\hline Compound & $\begin{array}{c}\text { EHOMO }_{\text {HOMO }} \\
(\mathrm{eV})^{\mathrm{a}}\end{array}$ & $\begin{array}{c}\text { ELUMO }_{\text {LUM }} \\
(e V)^{a}\end{array}$ & $\Delta E(\mathrm{eV})^{\mathrm{a}}$ & $\begin{array}{c}\lambda_{\mathrm{abs}}(\mathrm{nm}) \\
{\left[\varepsilon, 10^{3} \mathrm{~L} \cdot \mathrm{mol}^{-1} \cdot \mathrm{cm}^{-1}\right]}\end{array}$ & $\lambda_{\mathrm{PL}}(\mathrm{nm})^{b}$ & $\phi_{\mathrm{PL}}{ }^{\mathrm{c}}$ & $\begin{array}{c}\tau_{\text {ave }} \\
\text { (ns) } d\end{array}$ & $\begin{array}{c}\tau_{1} \\
\text { (ns) }\end{array}$ & $\begin{array}{c}\tau_{2} \\
(n s)\end{array}$ \\
\hline $\mathbf{O F}$ & -5.81 & -2.09 & 3.72 & 290 [29.5], $299[24.6], 307$ [25.0] & 328,447 & $<0.01$ & 2.63 & 0.82 & 5.08 \\
\hline 1F & -5.81 & -2.06 & 3.75 & $288[29.6], 297[24.5], 305[24.2]$ & 330,469 & $<0.01$ & 2.86 & 0.78 & 5.23 \\
\hline $3 F \mathbf{F}$ & -5.96 & -2.33 & 3.63 & $291[28.2], 307[25.0]$ & 343,431 & 0.01 & 2.55 & 0.86 & 4.84 \\
\hline $3 F b$ & -5.96 & -2.27 & 3.69 & $290[28.5], 307[25.3]$ & 340,433 & 0.01 & 2.12 & 0.75 & 4.92 \\
\hline $3 F c$ & -5.96 & -2.38 & 3.58 & 293 [27.7], 309 [25.2] & 349,436 & 0.01 & 2.37 & 0.86 & 5.93 \\
\hline $4 \mathrm{~F}$ & -6.07 & -2.50 & 3.57 & $300[28.5], 314$ [27.9] & 369,432 & 0.04 & 3.38 & 1.12 & 5.68 \\
\hline $5 \mathrm{~F}$ & -6.02 & -2.61 & 3.41 & $297[26.7], 311$ [26.1] & 406 & 0.08 & 2.82 & 1.41 & 5.42 \\
\hline
\end{tabular}

${ }^{\text {a }}$ Determined by cyclic voltammetry measured in $1.0 \times 10^{-3} \mathrm{~mol} \mathrm{~L}^{-1}$ acetonitrile solution. ${ }^{\mathrm{b}}$ Excitation by UV light at $\lambda_{\text {abs }} \cdot{ }^{\mathrm{c}}$ An integrating sphere was used. ${ }^{\mathrm{d}}$ PL lifetime $(\tau)$ monitored PL light at $\lambda_{\mathrm{PL}} . \tau_{\text {ave }}$ : average of PL lifetime, $\tau_{1}$ : PL lifetime for the first excited component and $\tau_{2}$ : for the second excited component.

As shown in Figure 3a, non-fluorinated tolane $\mathbf{0 F}$ and its fluorinated counterparts $1 \mathrm{~F}$ and $3 \mathrm{Fa}-\mathbf{c}$ containing three or fewer fluorine atoms exhibited absorption bands with two maxima $\left(\lambda_{\mathrm{abs}}\right)$ at approximately 290 and $307 \mathrm{~nm}$. With increasing the number of fluorine substituents, for example, $4 \mathrm{~F}$ and $5 \mathrm{~F}$ substituted with four and five fluorine atoms, respectively, in one of the aromatic rings of the tolane scaffold, a slight long-wavelength shift in $\lambda_{\mathrm{abs}}$ of approximately $10 \mathrm{~nm}$ was observed. Furthermore, the energy gap $(\Delta E)$ between the highest occupied molecular orbital (HOMO) and lowest unoccupied MO 
(LUMO), which was experimentally obtained via cyclic voltammetry (CV) measurements (Figure S35 and Table S3), decreased with the increasing number of fluorine substituents. Therefore, the red-shift in $\lambda_{\text {abs }}$ may be attributable to the decreased HOMO-LUMO energy gap, $\Delta E$. Additionally, the calculated data involving dipole moment in long molecular axis, HOMO and LUMO energies obtained from DFT calculations are also summarized in Table S6.

As shown in Figure $3 b$, in all the compounds, the maximum PL wavelength $\left(\lambda_{\mathrm{PL}}\right)$ was $328-406 \mathrm{~nm}$. In addition to the intense PL band observed in the short-wavelength region, interestingly, $\mathbf{0 F}$ and $1 \mathrm{~F}$ exhibited a weak PL band around $450 \mathrm{~nm}$. The two diphenylacetylene emission bands have been reported to originate from radiative deactivation via a $\pi \pi^{*}$ state for the short-wavelength band and a dark $\pi \sigma^{*}$ state for the long-wavelength band $[14,25]$. Furthermore, $3 \mathrm{~F}$ and $4 \mathrm{~F}$ exhibited a major PL band with $\lambda_{\mathrm{PL}}$ between 340 and $370 \mathrm{~nm}$, accompanied by a shoulder peak with $\lambda_{\mathrm{PL}}$ at approximately $430 \mathrm{~nm}$. In contrast, $5 \mathrm{~F}$ containing five fluorine substituents was found to exhibit a single PL band with $\lambda_{\mathrm{PL}}$ at $406 \mathrm{~nm}$. To gain more insights into these two PL bands, the excitation wavelength $\left(\lambda_{\text {ex }}\right)$-dependent PL behavior was investigated using $0 \mathrm{~F}$ as an example (Figure 3c). Excitation by higher energy light caused a gradual increase in the PL intensity in the long-wavelength region compared with the PL intensity observed upon excitation by lower energy light. In addition, as shown in Figure 3d, the excitation spectra observed at $\lambda_{\mathrm{PL}}$ at $447 \mathrm{~nm}$ were slightly blue-shifted in comparison with the excitation spectra observed at $328 \mathrm{~nm}$. This PL behavior likely originates from increased internal conversion from a higher-order excited state to a dark trans-bent excited state [14]. As a result of this major internal conversion process, the PL efficiency $\left(\phi_{\mathrm{PL}}\right)$ for $\mathbf{0 F}-\mathbf{3 F}$ appears to be extremely low $(<0.01)$. In the case of $4 \mathbf{F}$ and $\mathbf{5 F}$, a slight increase in $\phi_{\mathrm{PL}}(0.04$ and 0.08 for $4 \mathrm{~F}$ and $5 \mathrm{~F}$, respectively) was observed, owing to major contributions of the fast radiative process from the charge-transfer state, with the exception of a minor non-radiative process from the dark trans-bent excited state. In order to assess the radiative process for the tolane derivatives, we tested their PL lifetimes $\left(\tau_{\mathrm{PL}}\right)$. The $\tau$ values are depicted in Figure S33 and the data are also listed in Tables 1 and S2. The $\tau_{\mathrm{PL}}$ values of the THF solution containing $\mathbf{0 F}$ at $\lambda_{\mathrm{PL}}$ of $328 \mathrm{~nm}$ were approximately 0.82 and $5.08 \mathrm{~ns}$. The observed $\tau_{\mathrm{PL}}$ values were found to be different from those reported [25,26], which is likely due to the change of solvent polarity $[27,28]$. Compound $\mathbf{O F}$ in THF solution exhibited fluorescence due to light emission from two components at the singlet $S_{1}$ excited state. Similarly, the $\mathbf{1 F}-\mathbf{5 F}$ compounds also exhibited fluorescence, which stemmed from two luminescent components at the $S_{1}$ excited states.

We previously reported that tolane $5 \mathrm{~F}$ containing a pentafluorobenzene scaffold exhibited weak PL $\left(\phi_{\mathrm{PL}}=0.14\right)$ in the amorphous state [24]. After extensive trials, we were ultimately successful in producing single crystals of $5 \mathrm{~F}$. To our delight, we found that the PL efficiency of crystalline $5 \mathrm{~F}$ was four-fold higher $\left(\phi_{\mathrm{PL}}=0.51\right)$ compared to that of amorphous $5 \mathrm{~F}$. Based on these results, we focused on the PL characteristics of a series of tolane compounds $\mathbf{0 F}-\mathbf{5 F}$ in the crystalline-state. Figure 4 and Figure S32 shows the PL spectra and photographs obtained under both daylight and UV light conditions $\left(\lambda_{\mathrm{ex}}=365 \mathrm{~nm}\right)$. The photophysical data obtained are summarized in Table 2.

Table 2. Photophysical properties of tolanes $0 \mathrm{~F}-5 \mathrm{~F}$ in the crystalline states.

\begin{tabular}{cccccc}
\hline Compound & $\left.\boldsymbol{\lambda}_{\mathbf{P L}} \mathbf{( n m )}\right)^{\mathbf{a}}$ & $\boldsymbol{\phi}_{\mathbf{P L}}{ }^{\mathbf{b}}$ & $\boldsymbol{\tau}_{\mathbf{P L}}(\mathbf{n s})^{\mathbf{c}}$ & $\left.\boldsymbol{k}_{\mathbf{r}} \mathbf{( 1 0}^{\mathbf{8}} \mathbf{s}^{-\mathbf{1}}\right)^{\mathbf{d}}$ & $\boldsymbol{k}_{\boldsymbol{n} \mathbf{r}}\left(\mathbf{1 0}^{\mathbf{8}} \mathbf{s}^{-\mathbf{1}}\right)^{\mathbf{e}}$ \\
\hline $\mathbf{0 F}$ & 359 & 0.04 & 0.76 & 0.53 & 12.6 \\
$\mathbf{1 F}$ & 375 & 0.10 & 2.21 & 0.45 & 4.07 \\
$\mathbf{3 F a}$ & 368 & 0.31 & 2.12 & 1.46 & 3.25 \\
$\mathbf{3 F b}$ & 381 & 0.37 & 3.81 & 0.97 & 1.65 \\
$\mathbf{3 F c}$ & 374 & 0.14 & 1.13 & 1.24 & 7.61 \\
$\mathbf{4 F}$ & 375 & 0.04 & 0.77 & 0.52 & 12.5 \\
$\mathbf{5 F}$ & 465 & 0.51 & 2.37 & 2.15 & 2.07 \\
\hline
\end{tabular}

${ }^{\mathrm{a}} \lambda_{\mathrm{ex}}=300 \mathrm{~nm}$ for $\mathbf{0 F}-\mathbf{4 F}$ and $360 \mathrm{~nm}$ for $\mathbf{5 F} .{ }^{\mathrm{b}}$ An integrating sphere was used. ${ }^{\mathrm{c}}$ Monitored PL at $\lambda_{\mathrm{PL}} \cdot{ }^{\mathrm{d}}$ Radiative rate constant: $k_{\mathrm{r}}=\phi_{\mathrm{PL}} / \tau_{\mathrm{PL}}$. ${ }^{\mathrm{e}}$ Non-radiative rate constant: $k_{\mathrm{nr}}=\left(1-\phi_{\mathrm{PL}}\right) / \tau_{\mathrm{PL}}$. 


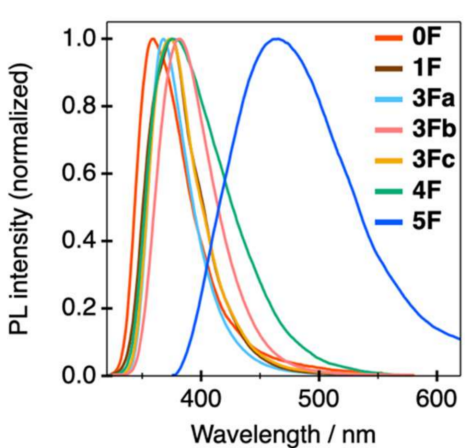

(a)

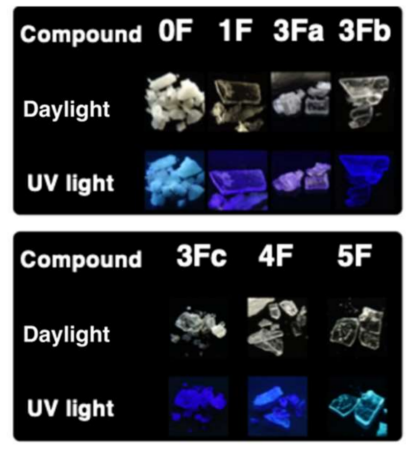

(b)

Figure 4. (a) PL spectra of $\mathbf{0 F}-\mathbf{5 F}$ in the crystalline states $\left(\lambda_{\mathrm{ex}}=300 \mathrm{~nm}\right.$ for $\mathbf{0 F}-\mathbf{4 F}$ and $360 \mathrm{~nm}$ for $\left.\mathbf{5 F}\right)$. (b) Photographs under daylight and UV light $\left(\lambda_{\mathrm{ex}}=365 \mathrm{~nm}\right)$.

Crystalline 5F exhibited a single band showing light-blue PL at $\lambda_{\mathrm{PL}}$ of around $465 \mathrm{~nm}$, whereas crystalline samples of $\mathbf{0 F}-\mathbf{4 F}$, which were prepared by recrystallization from $\mathrm{CH}_{2} \mathrm{Cl}_{2} / \mathrm{MeOH}(v / v=1 / 1)$, were found to exhibit deep-blue PL with $\lambda_{\mathrm{PL}}$ in the 359$381 \mathrm{~nm}$ range. As mentioned above, the $\phi_{\mathrm{PL}}$ of $5 \mathrm{~F}$ was as high as 0.51 , whereas the corresponding values for tolanes $\mathbf{0 F}, \mathbf{1 F}$, and $\mathbf{4 F}$ were observed to be quite low $(0.04,0.10$, and 0.04 for $\mathbf{0 F}, \mathbf{1 F}$, and $\mathbf{4 F}$, respectively). Considering the $\phi_{\mathrm{PL}}$ of a series of $\mathbf{3 F}$ containing three fluorine atoms at different substitution positions on the benzene ring, it is interesting that the $\phi_{\mathrm{PL}}$ was significantly affected by the position of the fluorine substituents. For example, 3Fa with three fluorine atoms at the 2, 3, and 4 positions and $3 \mathbf{F b}$ with three fluorine atoms at the 2,4 , and 6 positions exhibited relatively high $\phi_{P L}$ (up to 0.37), whereas $3 F c$ with three fluorine atoms at the 3,4 , and 5 positions exhibited low $\phi_{\mathrm{PL}}(0.14)$.

To understand why the $\phi_{\mathrm{PL}}$ values for $3 \mathbf{F a}-\mathbf{c}$ and $\mathbf{5 F}$ were higher than those for $\mathbf{0 F}$, $\mathbf{1 F}$, and $\mathbf{4 F}$, we performed $X$-ray crystallographic analyses for crystalline $3 \mathbf{F a}-\mathbf{c}, \mathbf{4 F}$, and $\mathbf{5 F}$, which were successfully obtained by recrystallization from a mixed solvent system containing $\mathrm{CH}_{2} \mathrm{Cl}_{2} / \mathrm{MeOH}$. Figure 5 shows the crystal packing structures of $3 \mathrm{Fa}-\mathrm{c}$ and the crystallographic data are summarized in Table S4.

Tolanes 3Fa-c containing three fluorine substituents were found to possess similar packing structures with four molecular units in a unit cell, in which three molecules, $A$ to $C$, existed in-plane (Figure $5 \mathrm{a}-\mathrm{f}$ ). Considering the intermolecular $\pi-\pi$ stacking interactions of $3 \mathbf{F a}-\mathbf{c}, 3 \mathbf{F a}$ exhibited two $\pi-\pi$ stacking interactions between molecules $\pi_{C} \cdots \pi_{D}$ with $334.1 \mathrm{pm}$ of interlayer distance on a one-to-one basis (Figure $5 \mathrm{~g}$ ). As shown in Figure $5 \mathrm{~h}, \mathrm{i}$, in contrast, $3 \mathrm{Fb}$ and $3 \mathrm{Fc}$ possessed two $\pi-\pi$ stacking interactions between two molecules $\pi_{C} \cdots \pi_{D} / \pi_{C} \cdots \pi_{E}$ with interlayer distances of 355.9 and $347.2 \mathrm{pm}$ for $3 \mathbf{F b}$ and 350.7 and $344.0 \mathrm{pm}$ for $\mathbf{3 F c}$, respectively [29,30]. In addition, in $\mathbf{3} \mathbf{F a}$ and $\mathbf{3 F b}$, three hydrogen bonding interactions were observed among the three molecules in the plane: $\mathrm{H}_{A} \cdots \mathrm{O}_{B} / \mathrm{H}_{B} \cdots \mathrm{F}_{C} / \mathrm{F}_{C} \cdots \mathrm{H}_{A}$ (Figure $5 \mathrm{j}, \mathrm{k}$ ). In contrast, 3Fc possessed only one $\mathrm{F}_{A} \cdots \mathrm{H}_{B}$ hydrogen bond without any other hydrogen bonding interactions (Figure 5l). Furthermore, the nonradiative rate constant $\left(k_{\mathrm{nr}}\right)$ values, which were calculated from $\tau_{\mathrm{PL}}$ in crystal (Figure S34), for $3 \mathbf{F a}$ and $3 \mathbf{F b}$ were approximately one-half or one-fifth of the corresponding value for 3 Fc. These results clearly indicate that the intermolecular $\pi-\pi$ stacking and hydrogen bonding interactions resulted in the formation of tight and rigid packing structures in the crystalline state, which likely suppresses nonradiative deactivation through molecular motions and results in strong PL in the crystal. Furthermore, 3Fa and $\mathbf{3 F b}$ with three hydrogen bonding interactions exhibited higher $\phi_{\mathrm{PL}}$ compared to $3 \mathrm{Fc}$, which had one hydrogen bond. 


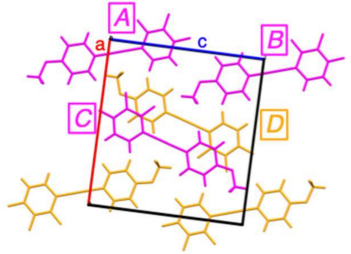

(a)

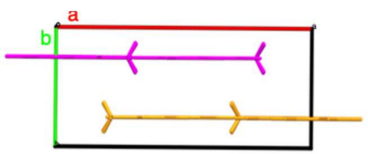

(d)

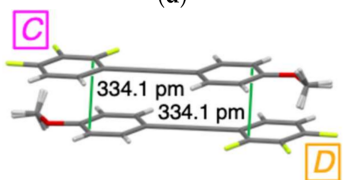

(g)

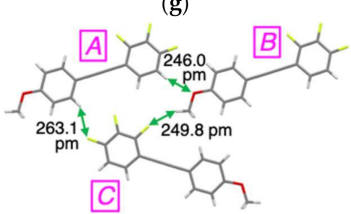

(j)

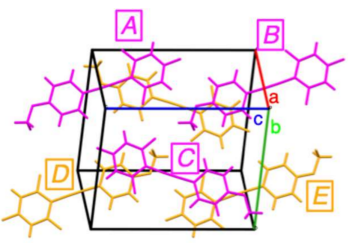

(b)

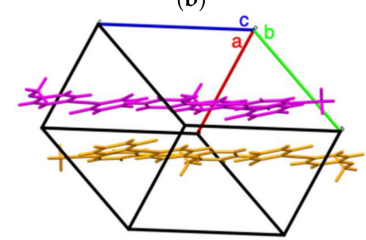

(e)

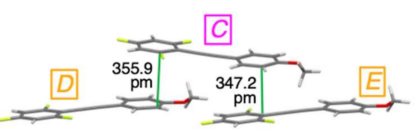

(h)

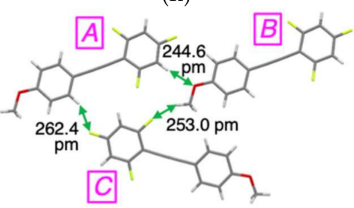

(k)

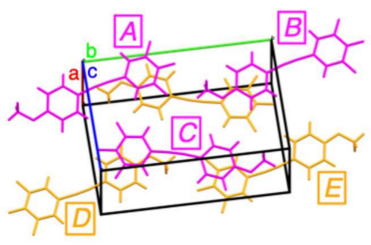

(c)

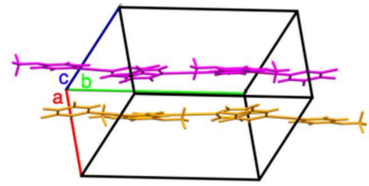

(f)

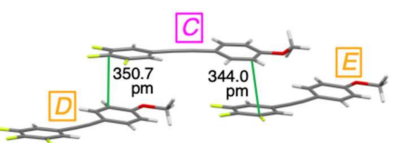

(i)

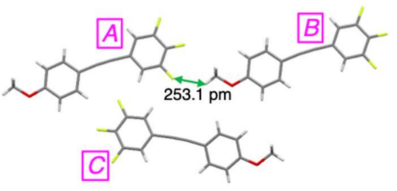

(1)

Figure 5. Crystal structure of $(\mathbf{a}, \mathbf{d}) 3 \mathbf{F a},(\mathbf{b}, \mathbf{e}) 3 \mathbf{F b}$, and $(\mathbf{c}, \mathbf{f}) 3 \mathbf{F c}$. Intermolecular interactions in $(\mathbf{g}, \mathbf{j})$ $3 \mathrm{Fa},(\mathbf{h}, \mathbf{k}) 3 \mathrm{Fb}$, and $(\mathbf{i}, \mathbf{l}) 3 \mathrm{Fc}$.

Figure 6 also shows the results of X-ray crystallographic analyses for $4 \mathrm{~F}$ and $5 \mathrm{~F}$, in which the crystallographic data are summarized in Table S5. Tolane $4 \mathbf{F}$ containing four fluorine atoms at the 2,3,5, and 6 positions was found to have a twisted structure with a dihedral angle of $65.6^{\circ}$ between the two aromatic rings connected to the alkyne moiety (Figure 6a). In the packing structures, two molecules were present in the unit cell (Figure 6c). One $\pi-\pi$ intermolecular interaction was observed between the $A \cdots B$ molecular units, with the closest interatomic distance $\left(\pi_{A} \cdots \pi_{B}\right)$ being $367.5 \mathrm{pm}$ (Figure 6e).

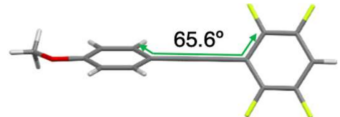

(a)

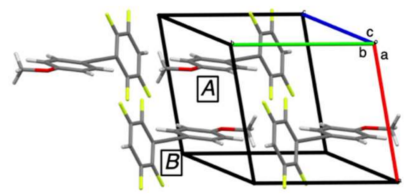

(c)

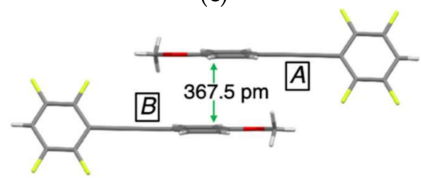

(e)

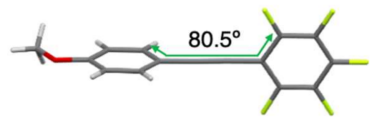

(b)

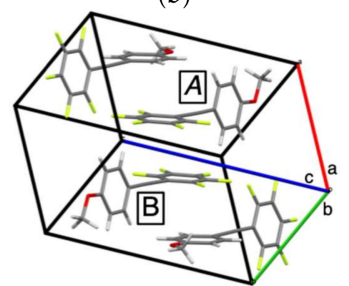

(d)

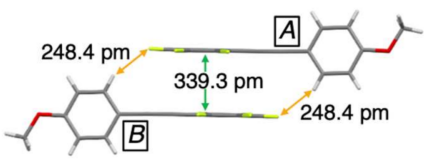

(f)

Figure 6. Crystal structures of (a) 4F, (b) 5F, packing structures of (c) $4 \mathrm{~F}$, (d) $5 \mathrm{~F}$, and intermolecular interactions of (e) $4 \mathrm{~F}$, (f) $5 \mathrm{~F}$. 
Similarly, the crystal structure of $5 \mathrm{~F}$ containing five fluorine atoms was also found to be twisted with a dihedral angle of $80.5^{\circ}$ between the two aromatic rings connected with the alkyne moiety; four molecular units were present in a unit cell (Figure $6 \mathrm{~b}, \mathrm{~d}$ ). Two molecular units $A \cdots B$ that existed in the central position were tightly held in place via a $\pi-\pi$ stacking interaction $\left(\pi_{A} \cdots \pi_{B}=339.3 \mathrm{pm}\right)$ and two hydrogen bonding interactions $\left(\mathrm{F}_{\mathrm{Ar}} \cdots \mathrm{H}_{\mathrm{Ar}}=248.4 \mathrm{pm}\right)$. The $\mathrm{H} \cdots \mathrm{F}$ distances in the hydrogen bonds were observed to be much shorter than those in $3 \mathbf{F a}-\mathbf{c}$, resulting in tighter and more rigid structures and the independent formation of dimer units. Owing to the tight dimer formation through multiple intermolecular interactions, the $k_{\mathrm{nr}}$ of $5 \mathrm{~F}\left(2.07 \times 10^{8} \mathrm{~s}^{-1}\right)$ was found to be one-sixth of the $k_{\mathrm{nr}}$ of $0 \mathrm{~F}$ or $4 \mathrm{~F}$. It can be concluded that the PL emission of $5 \mathrm{~F}$ in the crystal is likely to shift to the long-wavelength region and exhibit higher PL efficiency, compared to the other analogs. Judging from the relationship between the crystal structure and PL efficiency, the incorporation of fluorine substituents at either $2 / 6$ (ortho) and/or 4 (para) positions appears to be essential for efficient PL emission in the crystalline states.

Considering the $\phi_{\mathrm{PL}}$ change for $3 \mathrm{Fa}-\mathrm{c}$ in the solution and crystalline states, we tested their AIEE characteristics [31-33]. The PL spectra are shown in Figures 7 and S28-S32.

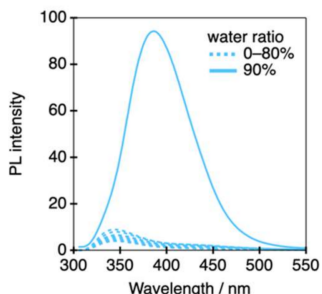

(a)

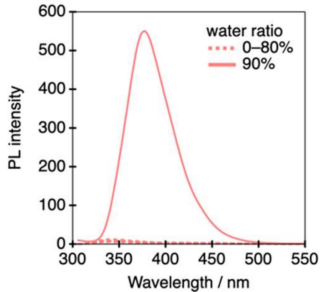

(c)

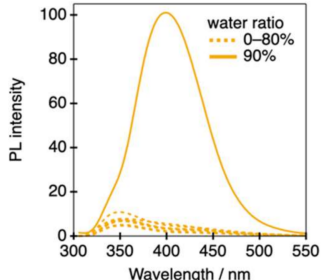

(e)

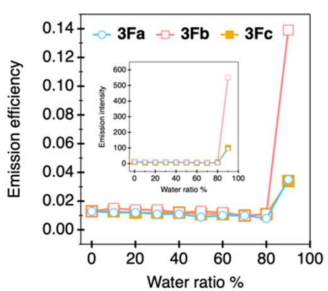

(g)

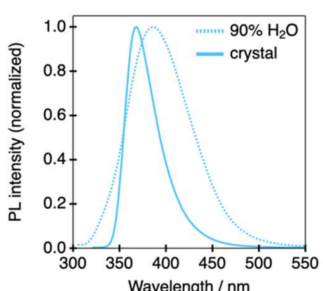

(b)

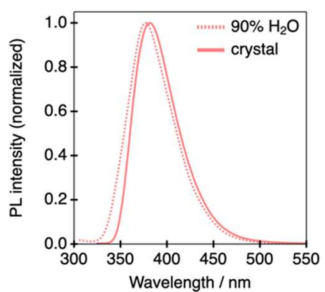

(d)

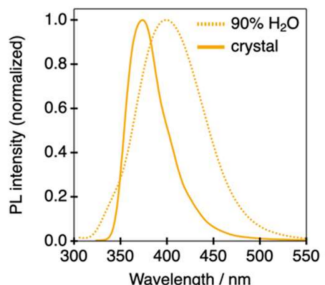

(f)

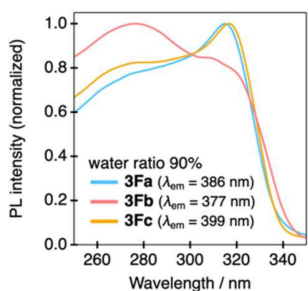

(h)

Figure 7. PL spectra of (a) 3Fa, (c) 3Fb, and (e) 3Fc in THF/water mixed solvent $\left(\lambda_{\mathrm{ex}}=290 \mathrm{~nm}\right.$ ). Differences in the PL spectra between the molecular aggregates obtained in the THF/water system and crystalline states for (b) $3 \mathbf{F a}$, (d) $3 \mathbf{F b}$, and (f) 3Fc. (g) Relationship between PL efficiency and additional water ratio (inset: relationship between PL intensity and additional water ratio). (h) Excitation spectra of the molecular aggregates for $3 \mathbf{F a}-\mathbf{c}$ obtained after the addition of $90 \%$ water. 
As shown in Figure 7a,c,e, the PL intensities of 3Fa-c did not change at all with up to $80 \%$ water addition, whereas the PL intensities significantly increased upon the addition of $90 \%$ water. In $3 \mathbf{F b}, \phi_{\mathrm{PL}}$ markedly improved to 0.14 when the water amount reached $90 \%$, whereas $\phi_{\mathrm{PL}}$ only slightly improved to 0.04 and 0.03 in 3Fa and 3Fc (Figure $7 \mathrm{~g}$ ), respectively, which suggests that the molecular aggregates formed in the solution upon water addition depend on the substitution position of the fluorine atoms. Furthermore, as shown in Figure $7 \mathrm{~h}$, this is also supported by the fact that only $\mathbf{3 F b}$ exhibited a different excitation spectrum compared to $3 \mathbf{F a}$ and $3 \mathbf{F c}$ at $90 \%$ water content. Comparing the PL spectral shapes for the molecular aggregates formed in THF/water mixtures with those formed in the crystalline state, the $\lambda_{\mathrm{PL}}$ values for $3 \mathrm{Fa}$ and $3 \mathrm{Fc}$ were slightly red-shifted in the THF/water mixtures, whereas in the crystalline state, only $\mathbf{3 F b}$ exhibited a similar spectral shape (Figure $7 \mathrm{~b}, \mathrm{~d}, \mathrm{f}$ ). The change in the spectral shape likely originates from the changes in the molecular aggregated structures, which clearly indicate that the PL characteristics can be modulated by altering the molecular aggregates.

\section{Materials and Methods}

\subsection{Materials}

The ${ }^{1} \mathrm{H}-\mathrm{NMR}(400 \mathrm{MHz})$ and ${ }^{13} \mathrm{C}-\mathrm{NMR}(100 \mathrm{MHz})$ spectra were obtained using an AVANCE III 400 NMR spectrometer (Bruker, Rheinstetten, Germany) in chloroform-d $\left(\mathrm{CDCl}_{3}\right)$ solution, and the chemical shifts are reported in parts per million (ppm) using the residual protons in the NMR solvent. The ${ }^{19} \mathrm{~F}-\mathrm{NMR}(376 \mathrm{MHz})$ spectra were obtained using an AVANCE III 400 NMR spectrometer (Bruker, Rheinstetten, Germany) in $\mathrm{CDCl}_{3}$ solution with $\mathrm{CFCl}_{3}\left(\delta_{\mathrm{F}}=0 \mathrm{ppm}\right)$ as an internal standard. Infrared (IR) spectra were recorded using the KBr method with an FTIR-4100 type A spectrometer (JASCO, Tokyo, Japan). All the spectra are reported in terms of wavenumber $\left(\mathrm{cm}^{-1}\right)$. High-resolution mass spectra (HRMS) were recorded on a JMS700MS spectrometer (JEOL, Tokyo, Japan) using the fast atom bombardment (FAB) method. All the chemicals, including solvents, were of reagent grade and were purified in the usual manner prior to use. Column chromatography was carried out on silica gel (FUJIFILM Wako Pure Chemical Corporation, Wakogel ${ }^{\circledR} 60$ N, 38-100 $\mu \mathrm{m}$ ) and thin-layer chromatography (TLC) was performed on silica gel TLC plates (Merck, Silica gel 60F 254 ; Kenilworth, NJ, USA).

\subsection{General Synthesis Procedure for the Pd(0)-Catalyzed Sonogashira Cross-Coupling Reaction}

In a flask, an aromatic halide, 4-ethynylanisole, dichlorobis(triphenylphosphine)palladium(II), triphenylphosphine, copper(I) iodide, and triethylamine, and the suspended solution were stirred at $60{ }^{\circ} \mathrm{C}$ overnight. After the reaction times indicated, the precipitate formed during the reaction was separated by atmospheric filtration, while the filtrate was poured into a saturated aqueous ammonium chloride solution. The crude product was extracted with ethyl acetate (EtOAc) three times, and the combined organic layer was washed once with brine. The collected organic layer was dried over anhydrous $\mathrm{Na}_{2} \mathrm{SO}_{4}$, which was separated by filtration. The filtrate was evaporated in vacuo and subjected to silica gel column chromatography (eluent: hexane/EtOAc $=20 / 1$ ), followed by recrystallization from $\mathrm{CH}_{2} \mathrm{Cl}_{2} / \mathrm{MeOH}(v / v=1 / 1)$, to obtain the desired product in a $46-94 \%$ yield.

\subsection{1. [2-(4-methoxyphenyl)ethyn-1-yl]benzene (0F)}

Yield: $94 \%$ (White solid); m.p.: $59.1-60.3{ }^{\circ} \mathrm{C} ;{ }^{1} \mathrm{H}-\mathrm{NMR}\left(\mathrm{CDCl}_{3}\right): \delta 3.83$ (s, 3H), 6.88 $(\mathrm{d}, J=8.9 \mathrm{~Hz}, 2 \mathrm{H}), 7.30-7.36(\mathrm{~m}, 3 \mathrm{H}), 7.46-7.52(\mathrm{~m}, 4 \mathrm{H})$. The spectral data were fully in agreement with the reported data [34].

\subsubsection{1-Fluoro-4-[2-(4-methoxyphenyl)ethyn-1-yl]benzene (1F)}

Yield: 88\% (White solid); m.p.: 89.2-91.3 ${ }^{\circ} \mathrm{C} ;{ }^{1} \mathrm{H}-\mathrm{NMR}\left(\mathrm{CDCl}_{3}\right): \delta 3.84(\mathrm{~s}, 3 \mathrm{H}), 6.88(\mathrm{~d}$, $J=8.9 \mathrm{~Hz}, 2 \mathrm{H}), 7.03(\mathrm{t}, J=8.8 \mathrm{~Hz}, 2 \mathrm{H}), 7.44-7.50(\mathrm{~m}, 4 \mathrm{H})$. The spectral data were fully in agreement with the reported data [35]. 


\subsubsection{1,2,3-Trifluoro-4-[2-(4-methoxyphenyl)ethyn-1-yl]benzene (3Fa)}

Yield: $65 \%$ (White solid); m.p.: $75.0-76.3{ }^{\circ} \mathrm{C} ;{ }^{1} \mathrm{H}-\mathrm{NMR}\left(\mathrm{CDCl}_{3}\right): \delta 3.84(\mathrm{~s}, 3 \mathrm{H}), 6.89$ $(\mathrm{d}, J=8.9 \mathrm{~Hz}, 2 \mathrm{H}), 7.18-7.25(\mathrm{~m}, 1 \mathrm{H}), 7.18-7.25(\mathrm{~m}, 1 \mathrm{H}), 7.49(\mathrm{~d}, J=8.9 \mathrm{~Hz}, 2 \mathrm{H}) ;{ }^{19} \mathrm{~F}-$ $\operatorname{NMR}\left(\mathrm{CDCl}_{3}\right)$ : $\delta-131.16$ (ddd, $\left.J=20.3,8.6,6.8 \mathrm{~Hz}, 1 \mathrm{~F}\right),-133.15$ to $-133.04(\mathrm{~m}, 1 \mathrm{~F}),-160.17$ $(\operatorname{tdd}, J=20.4,6.7,2.1 \mathrm{~Hz}, 1 \mathrm{~F})$. The spectral data were fully in agreement with the reported data [36].

\subsubsection{1,3,5-Trifluoro-4-[2-(4-methoxyphenyl)ethyn-1-yl]benzene (3Fb)}

Yield: $46 \%$ (White solid); m.p.: 96.5-97.5 ${ }^{\circ} \mathrm{C} ;{ }^{1} \mathrm{H}-\mathrm{NMR}\left(\mathrm{CDCl}_{3}\right): \delta 3.84(\mathrm{~s}, 3 \mathrm{H}), 6.68-6.75$ $(\mathrm{m}, 2 \mathrm{H}), 6.89(\mathrm{~d}, J=8.9 \mathrm{~Hz}, 2 \mathrm{H}), 7.51(\mathrm{~d}, J=8.9 \mathrm{~Hz}, 2 \mathrm{H}) ;{ }^{13} \mathrm{C}-\mathrm{NMR}\left(\mathrm{CDCl}_{3}\right): \delta 55.4,73.9$, 99.1-99.2 (m), $101.9(\mathrm{dd}, J=19.8,4.9 \mathrm{~Hz}), 100.3-100.8(\mathrm{~m}), 114.2,114.6,133.4,160.3,162.1(\mathrm{dt}$, $J=250.5,14.6 \mathrm{~Hz}), 163.3(\mathrm{dq}, J=252.6,7.7 \mathrm{~Hz}) ;{ }^{19} \mathrm{~F}-\mathrm{NMR}\left(\mathrm{CDCl}_{3}\right): \delta-105.24(\mathrm{t}, J=7.5 \mathrm{~Hz}$, 2F), -106.49 to $-106.41(\mathrm{~m}, 1 \mathrm{~F})$; IR (KBr): v 3095, 3077, 2841, 2362, 2223, 1884, 1636, 1590, 1520, 1440, 1250, 1031, $827 \mathrm{~cm}^{-1}$; HRMS: (FAB+) $m / z[\mathrm{M}]^{+}$calcd for $\mathrm{C}_{15} \mathrm{H}_{9} \mathrm{~F}_{3} \mathrm{O}: 262.0605$; found: 262.0604 .

\subsubsection{1,2,6-Trifluoro-4-[2-(4-methoxyphenyl)ethyn-1-yl]benzene (3Fc)}

Yield: 59\% (White solid); m.p.: 66.8-67.9 ${ }^{\circ} \mathrm{C} ;{ }^{1} \mathrm{H}-\mathrm{NMR}\left(\mathrm{CDCl}_{3}\right): \delta 3.84(\mathrm{~s}, 3 \mathrm{H}), 6.88(\mathrm{~d}$, $J=8.9 \mathrm{~Hz}, 2 \mathrm{H}), 7.11(\mathrm{dd}, J=8.2,6.6 \mathrm{~Hz}, 2 \mathrm{H}), 7.45(\mathrm{~d}, J=8.9,2 \mathrm{H}) ;{ }^{13} \mathrm{C}-\mathrm{NMR}\left(\mathrm{CDCl}_{3}\right): \delta 55.4$, $85.3(\mathrm{dd}, J=6.0,3.0 \mathrm{~Hz}), 91.2(\mathrm{~d}, J=2.0 \mathrm{~Hz}), 114.2,114.3,115.8(\mathrm{dd}, J=16.2,6.3 \mathrm{~Hz}), 119.8$ $(\mathrm{ddd}, J=15.2,10.2,5.2), 133.3,140.1(\mathrm{dt}, J=252.8,15.3), 151.11(\mathrm{ddd}, J=248.7,10.2,4.5 \mathrm{~Hz})$, $160.3 ;{ }^{19} \mathrm{~F}-\mathrm{NMR}\left(\mathrm{CDCl}_{3}\right): \delta-134.86(\mathrm{dd}, J=20.4,8.0 \mathrm{~Hz}, 2 \mathrm{~F}),-160.04(\mathrm{tt}, J=20.5,6.4 \mathrm{~Hz}, 1 \mathrm{~F})$; IR (KBr): v 3098, 3023, 2845, 2360, 2343, 2213, 1608, 1527, 1508, 1430, 1252, 1044, $832 \mathrm{~cm}^{-1}$; HRMS: $(\mathrm{FAB}+) \mathrm{m} / z$ [M] ${ }^{+}$calcd for $\mathrm{C}_{15} \mathrm{H}_{9} \mathrm{~F}_{3} \mathrm{O}: 262.0605$; found: 262.0604 .

\subsubsection{2,3,5,6-Tetrafluoro-4-[2-(4-methoxyphenyl)ethyn-1-yl]benzene (4F)}

Yield: $65 \%$ (White solid); m.p.: 76.8-77.4 ${ }^{\circ} \mathrm{C} ;{ }^{1} \mathrm{H}-\mathrm{NMR}\left(\mathrm{CDCl}_{3}\right): \delta 3.85(\mathrm{~s}, 3 \mathrm{H}), 6.91$ $(\mathrm{d}, J=8.9 \mathrm{~Hz}, 2 \mathrm{H}), 7.02(\mathrm{ddt}, J=17.0,9.7,7.3 \mathrm{~Hz}, 1 \mathrm{H}), 7.53(\mathrm{~d}, J=8.9 \mathrm{~Hz}, 2 \mathrm{H}) ;{ }^{13} \mathrm{C}-\mathrm{NMR}$ $\left(\mathrm{CDCl}_{3}\right): \delta 55.5,73.5(\mathrm{dd}, J=4.0,4.0 \mathrm{~Hz}), 102.3(\mathrm{dd}, J=3.6,3.6 \mathrm{~Hz}), 105.5-106.1(\mathrm{~m}), 105.7$ $(\mathrm{dd}, J=22.9,22.9 \mathrm{~Hz}), 113.8,114.3,133.7,145.9(\mathrm{dm}, J=246.5), 146.7$ (dddd, $J=250.1$, 14.4, 3.5, 3.5 Hz), $160.8 ;{ }^{19} \mathrm{~F}-\mathrm{NMR}\left(\mathrm{CDCl}_{3}\right): \delta-137.63(\mathrm{dq}, J=20.0,7.4 \mathrm{~Hz}, 2 \mathrm{~F}),-139.75$ (qui, $J=11.8 \mathrm{~Hz}, 2 \mathrm{~F}) ; \mathrm{IR}(\mathrm{KBr}): \vee \mathrm{3103}, 3079,2964,2839,2361,2224,1604,1491,1398,1255,1173$, 1032, $930 \mathrm{~cm}^{-1}$; HRMS: (FAB+) $\mathrm{m} / z$ [M] $]^{+}$calcd for $\mathrm{C}_{15} \mathrm{H}_{8} \mathrm{~F}_{4} \mathrm{O}: 280.0511$; found: 280.0503 .

\subsection{Photophysical Measurements}

UV/vis absorption spectra were recorded on a V-530 absorption spectrometer (JASCO, Tokyo, Japan). PL spectra in the solution and crystal forms were acquired using an FP-6600 fluorescence spectrometer (JASCO, Tokyo, Japan). The absolute quantum yields in solution and crystal forms were measured using the Quantaurus-QY measurement system C1134701 (Hamamatsu Photonics, Hamamatsu, Japan). The PL lifetime was obtained using a Quantaurus-Tau fluorescence lifetime spectrometer C11367-34 (Hamamatsu Photonics, Hamamatsu, Japan).

\subsection{Single Crystal X-ray Diffraction}

Single crystal X-ray diffraction spectra were recorded on an XtaLAB AFC11 diffractometer (Rigaku, Tokyo, Japan). The reflection data were integrated, scaled, and averaged using CrysAlisPro program (ver. 1.171.39.43a, Rigaku Corporation, Akishima, Japan) [37]. Empirical absorption corrections were applied using the SCALE 3 ABSPACK scaling algorithm (CrysAlisPro). The structures were identified by a direct method (SHELXT2018/2 [38]) and refined using a full matrix least squares method (SHELXL-2018/3 [39]) visualized by Olex2 [40]. The crystallographic data were deposited into the Cambridge Crystallographic Data Centre (CCDC) database (CCDC 2070935 for 3Fa, 2070936 for 3Fb, 2070937 for $3 \mathbf{F c}$, 2070938 for $4 \mathbf{F}$ and 2070939 for $\mathbf{5 F}$ ). These data can be obtained free 
of charge from the CCDC via www.ccdc.cam.ac.uk/data_request/cif (accessed on 13 April 2021).

\subsection{Cyclic Voltammetry}

Cyclic voltammetry (CV) measurements were carried out using an ECstat-101 potentiostat (EC frontier, Kyoto, Japan) with glassy carbon, $\mathrm{Pt}$, and $\mathrm{Ag} / \mathrm{AgCl}$ as the working, counter, and reference electrodes, respectively. Ferrocene $(\mathrm{Fc}) /$ ferrocenium $\left(\mathrm{Fc}^{+}\right)$was used as an external reference, while tetrabutylammonium hexafluorophosphate $\left(\mathrm{Bu}_{4} \mathrm{NPF}_{6}\right)$ was used as the supporting electrolyte $\left(0.1 \mathrm{~mol} \mathrm{~L}^{-1}\right)$. All the measurements were performed after argon bubbling for $30 \mathrm{~min}$ in $1 \times 10^{-3} \mathrm{~mol} \mathrm{~L}^{-1}$ acetonitrile solution, with a scan rate of $50 \mathrm{mV} \mathrm{s}^{-1}$. HOMO and LUMO energy levels were estimated from the onset potentials of the oxidation $\left(E_{O x}\right)$ and reduction $\left(E_{R e d}\right)$ waves (versus $\left.\mathrm{FC}_{\mathrm{C}} / \mathrm{Fc}^{+}\right)$using the following equation: $E_{\mathrm{HOMO}}=-4.80-E_{\mathrm{Ox}}, E_{\mathrm{LUMO}}=-4.80-E_{\mathrm{Red}}, \Delta E=E_{\mathrm{LUMO}}-E_{\mathrm{HOMO}}$.

\section{Conclusions}

To gain insights into the structure-property relationships of fluorinated tolanes, we synthesized various tolanes with and without fluorine substituents $(\mathbf{0 F}-\mathbf{5 F})$. We evaluated the photophysical properties and crystal structures of these compounds in detail. During extensive investigations, all the derivatives were found to be non-emissive in dilute THF solution, with tight molecular packing structures formed via $\pi-\pi$ stacking as well as hydrogen bonding interactions. Interestingly, tight molecular aggregates were formed when the fluorine substituents were incorporated at the ortho and para positions. The fluorinated tolanes containing fluorine substituents at these positions were found to emit PL efficiently, resulting in $\phi_{\mathrm{PL}}$ values in the $0.31-0.51$ range. The range of PL behavior exhibited in solution (non-emissive) and in the crystalline state (emissive) piqued our interest to study the aggregation-induced emission enhancement characteristics. From the PL investigations of $3 \mathbf{F}$ (containing three fluorine substituents) in THF/water mixtures, we found a significant enhancement in the PL intensity upon adding $90 \%$ water, although the PL intensity was low, at approximately 0.01 , when the amount of water was below $80 \%$. The PL spectral shape was different from that in the crystalline state, obtained by recrystallization. It was found that the PL characteristics of fluorinated tolane $3 F$ could be tuned by altering the molecular aggregates, which is promising for fabricating materials with tunable PL properties.

Supplementary Materials: The following are available online, Figure S1: Synthetic method of the target compounds; Figures S2-S15: NMR spectra of new compounds; Figures S16-S22: UV-vis and PL spectra in THF solution; Figure S23: UV-vis and PL spectra in hexane solution; Figure S24: UV-vis and PL spectra in $\mathrm{CH}_{2} \mathrm{Cl}_{2}$ solution; Figures S25-S27: solvatochromic PL properties of $3 \mathbf{F a}-\mathbf{c}$; Figures S28-S30: PL spectra of 3Fa-3Fc in THF/water mixed solution; Figure S31: photographs of the PL behavior for $3 \mathbf{F a}-3 \mathbf{F c}$ in the mixed solution; Figure S32: PL spectra of $\mathbf{0 F - 5 F}$ in crystal; Figures S33 and S34: PL lifetime decay curve; Figure S35: CV curve of 0F-5F; Table S1: photophysical data of 0F-5F; Table S2: PL lifetime of $\mathbf{0 F - 5 F}$ in THF solution; Table S3: Electrical properties obtained by CV measurement; Tables S4 and S5: crystallographic data of $3 \mathbf{F a}-3 \mathbf{F c}, 4 \mathbf{F}$ and $5 \mathbf{F}$; Table S6: Results of DFT calculations.

Author Contributions: Conceptualization, M.M. and S.Y.; methodology, M.M. and S.Y.; validation, M.M. and S.Y.; investigation, M.M. and S.Y.; writing-original draft preparation, M.M. and S.Y.; writing-review and editing, M.M., S.Y. and T.K.; visualization, M.M. and S.Y.; supervision, S.Y.; project administration, S.Y. All authors have read and agreed to the published version of the manuscript.

Funding: This research received no external funding.

Institutional Review Board Statement: Not applicable.

Informed Consent Statement: Not applicable.

Data Availability Statement: Data is contained within the article or supplementary material. 
Acknowledgments: A part of this work was conducted at the Institute for Molecular Science, supported by the Nanotechnology Platform Program <Molecule and Material Synthesis $>$ (JPMXP09S20MS1026) of the Ministry of Education, Culture, Sports, Science and Technology (MEXT), Japan.

Conflicts of Interest: The authors declare no conflict of interest.

Sample Availability: Samples of all compounds are available from the authors.

\section{References}

1. Gutmann, M.; Gudipati, M.; Schoenzart, P.F.; Hohlneicher, G. Electronic spectra of matrix-isolated tolan: Site selective one- and two-photon spectra. J. Phys. Chem. 1992, 96, 2433-2442. [CrossRef]

2. Suzuki, T.; Nakamura, M.; Isozaki, T.; Ikoma, T. “Dark” Excited States of Diphenylacetylene Studied by Nonresonant Two-Photon Excitation Optical-Probing Photoacoustic Spectroscopy. Int. J. Thermophys. 2012, 33, 2046-2054. [CrossRef]

3. Isozaki, T.; Oba, H.; Ikoma, T.; Suzuki, T. Simultaneous two-photon absorption to gerade excited singlet states of diphenylacetylene and diphenylbutadiyne using optical-probing photoacoustic spectroscopy. J. Phys. Chem. A 2016, 120, 6137-6145. [CrossRef]

4. Young, D.D.; Scharrer, E.; Yoa, M.V. Synthesis and phase behavior of liquid crystalline diphenylacetylene derivatives possessing high clearing temperatures. Mol. Cryst. Liq. Cryst. 2004, 408, 21-31. [CrossRef]

5. Cheng, Z.; Zang, Y.; Li, Y.; Li, B.; Hu, C.; Li, H.; Yang, Y. A chiral luminescent liquid crystal with a tolane unit. Liq. Cryst. 2016, 43, 777-782. [CrossRef]

6. Arakawa, Y.; Inui, S.; Tsuji, H. Novel diphenylacetylene-based room-temperature liquid crystalline molecules with alkylthio groups, and investigation of the role for terminal alkyl chains in mesogenic incidence and tendency. Liq. Cryst. 2017, 45, 811-820. [CrossRef]

7. Yang, W.-Y.; Roy, S.; Phrathep, B.; Rengert, Z.; Kenworthy, R.; Zorio, D.A.R.; Alabugin, I.V. Engineering pH-gated transi-tions for selective and efficient double-strand DNA photocleavage in hypoxic tumors. J. Med. Chem. 2011, 54, 8501-8516. [CrossRef] [PubMed]

8. Yang, W.-Y.; Marrone, S.A.; Minors, N.; Zorio, D.A.R.; Alabugin, I.V. Fine-tuning alkyne cycloadditions: Insights into photochemistry responsible for the double-strand DNA cleavage via structural perturbations in diaryl alkyne conjugates. Beilstein J. Org. Chem. 2011, 7, 813-823. [CrossRef] [PubMed]

9. Do, T.T.; Chavhan, S.; Subbiah, J.; Ou, T.-H.; Manzhos, S.; Jones, D.J.; Bell, J.M.; Jou, J.-H.; Sonar, P.M. Naphthalimide end-capped diphenylacetylene: A versatile organic semiconductor for blue light emitting diodes and a donor or an acceptor for solar cells. New J. Chem. 2019, 43, 9243-9254. [CrossRef]

10. Ferrante, C.; Kensy, U.; Dick, B. Does diphenylacetylene (tolan) fluorescence from its second excited singlet state? Sem-iempirical MO calculations and fluorescence quantum yield measurements. J. Phys. Chem. 1993, 97, 13457-13463. [CrossRef]

11. Zgierski, M.Z.; Lim, E.C. Nature of the 'dark' state in diphenylacetylene and related molecules: State switch from the linear $\pi \pi^{*}$ state to the bent $\pi \sigma^{*}$ state. Chem. Phys. Lett. 2004, 387, 352-355. [CrossRef]

12. Saltiel, J.; Kumar, V.K.R. Photophysics of diphenylacetylene: Light from the "dark state". J. Phys. Chem. A 2012, 116, 10548-10558. [CrossRef] [PubMed]

13. Karunakaran, V.; Prabhu, D.D.; Das, S. Optical investigation of self-aggregation of a tetrazole-substituted diphenylacety-lene derivative: Steady and excited state dynamics in solid and solution state. J. Phys. Chem. C 2013, 117, 9404-9415. [CrossRef]

14. Wierzbicka, M.; Bylińska, I.; Czaplewski, C.; Wiczk, W. Experimental and theoretical studies of the spectroscopic properties of simple symmetrically substituted diphenylacetylene derivatives. RSC Adv. 2015, 5, 29294-29303. [CrossRef]

15. Kozhemyakin, Y.; Krämer, M.; Rominger, F.; Dreuw, A.; Bunz, U.H.F. A Tethered Tolane: Twisting the Excited State. Chem. A Eur. J. 2018, 24, 15219-15222. [CrossRef]

16. Menning, S.; Krämer, M.; Duckworth, A.; Rominger, F.; Beeby, A.; Dreuw, A.; Bunz, U.H.F. Bridged Tolanes: A Twisted Tale. J. Org. Chem. 2014, 79, 6571-6578. [CrossRef] [PubMed]

17. Tong, J.; Wang, Y.J.; Wang, Z.; Sun, J.Z.; Tang, B.Z. Crystallization-Induced Emission Enhancement of a Simple Tolane-Based Mesogenic Luminogen. J. Phys. Chem. C 2015, 119, 21875-21881. [CrossRef]

18. Zang, Y.; Li, Y.; Li, B.; Li, H.; Yang, Y. Light emission properties and self-assembly of a tolane-based luminogen. RSC Adv. 2015, 5, 38690-38695. [CrossRef]

19. Bu, X.; Zhu, D.; Liu, T.; Li, Y.; Cai, S.; Wang, H.; Zeng, Z. Approach to tuned emitting color of luminescent liquid crystals with substituted fluoropyrrole acceptor unit. Dye. Pigment. 2017, 145, 324-330. [CrossRef]

20. Kirsch, P. Modern Fluoroorganic Chemistry: Synthesis, Reactivity, Applications, 2nd ed.; Wiley-VCH: Weinheim, Germany, 2013; pp. 7-21.

21. O'Hagan, D. Understanding organofluorine chemistry. An introduction to the C-F bond. Chem. Soc. Rev. 2007, 37, 308-319. [CrossRef]

22. Yamada, S.; Uto, E.; Agou, T.; Kubota, T.; Konno, T. Fluorinated tolane dyads with alkylene linkage: Synthesis and eval-uation of photophysical characteristics. Crystals 2020, 10, 711. [CrossRef]

23. Morita, M.; Yamada, S.; Konno, T. Fluorine-induced emission enhancement of tolanes via formation of tight molecular aggregates. New J. Chem. 2020, 44, 6704-6708. [CrossRef] 
24. Yamada, S.; Mitsuda, A.; Miyano, K.; Tanaka, T.; Morita, M.; Agou, T.; Kubota, T.; Konno, T. Development of novel sol-id-state light-emitting materials based on pentafluorinated tolane fluorophores. ACS Omega 2018, 3, 9105-9113. [CrossRef] [PubMed]

25. Melnikov, A.R.; Davydova, M.P.; Sherin, P.S.; Korolev, V.V.; Stepanov, A.A.; Kalneus, E.V.; Benassi, E.; Vasilevsky, S.F.; Stass, D.V. X-Ray Generated Recombination Exciplexes of Substituted Diphenylacetylenes with Tertiary Amines: A Ver-satile Experimental Vehicle for Targeted Creation of Deep-Blue Electroluminescent Systems. J. Phys. Chem. A 2018, 122, 1235-1252. [CrossRef]

26. Hirata, Y.; Okada, T.; Nomoto, T. Higher excited singlet state of diphenylacetylene in solution phase. Chem. Phys. Lett. 1993, 209, 397-402. [CrossRef]

27. Khundkar, L.R.; Stiegman, A.E.; Perry, J.W. Solvent-tuned intramolecular charge-recombination rates in a conjugated donoracceptor molecule. J. Phys. Chem. 1990, 94, 1224-1226. [CrossRef]

28. Szyszkowska, M.; Bylińska, I.; Wiczk, W. Influence of an electron-acceptor substituent type on the photophysical properties of unsymmetrically substituted diphenylacetylene. J. Photochem. Photobiol. A Chem. 2016, 326, 76-88. [CrossRef]

29. Soloshonok, V.A.; Hayashi, T. Gold(I)-catalyzed asymmetric aldol reaction of methyl isocyanoacetate with fluorinated benzaldehydes. Tetrahedron Lett. 1994, 35, 2713-2716. [CrossRef]

30. Soloshonok, V.A.; Hayashi, T. Gold(I)-catalyzed asymmetric aldol reactions of fluorinated benzaldehydes with an $\alpha-$ isocyanoacetamide. Tetrahedron Asymmetry 1994, 5, 1091-1094. [CrossRef]

31. Zhang, H.; Zhao, Z.; Turley, A.T.; Wang, L.; McGonigal, P.R.; Tu, Y.; Li, Y.; Wang, Z.; Kwok, R.T.K.; Lam, J.W.Y.; et al. Aggregate Science: From Structures to Properties. Adv. Mater. 2020, 32, 2001457. [CrossRef] [PubMed]

32. Feng, H.-T.; Liu, C.; Li, Q.; Zhang, H.; Lam, J.W.Y.; Tang, B.Z. Structure, Assembly, and Function of (Latent)-Chiral AIEgens. ACS Mater. Lett. 2019, 1, 192-202. [CrossRef]

33. He, Z.; Ke, C.; Tang, B.Z. Journey of Aggregation-Induced Emission Research. ACS Omega 2018, 3, 3267-3277. [CrossRef]

34. Nielsen, A.; Kuzmanich, G.; Garcia-Garibay, M.A. Quantum Chain Reaction of Tethered Diarylcyclopropenones in the Solid State and Their Distance-Dependence in Solution Reveal a Dexter S2-S2Energy-Transfer Mechanism. J. Phys. Chem. A 2014, 118, 1858-1863. [CrossRef] [PubMed]

35. Rao, M.L.N.; Jadhav, D.N.; Dasgupta, P. Pd-Catalyzed Domino Synthesis of Internal Alkynes Using Triarylbismuths as Multicoupling Organometallic Nucleophiles. Org. Lett. 2010, 12, 2048-2051. [CrossRef] [PubMed]

36. Severin, R.; Reimer, J.; Doye, S. One-Pot Procedure for the Synthesis of Unsymmetrical Diarylalkynes. J. Org. Chem. 2010, 75, 3518-3521. [CrossRef]

37. CrysAlisPro 1.171.39.43a. Rigaku Oxford Diffraction; Rigaku Corporation: Akishima, Japan, 2015.

38. Sheldrick, G.M. SHELXT- Integrated space-group and crystal-structure determination. Acta Cryst. 2015, 71, 3-8. [CrossRef]

39. Sheldrick, G.M. Crystal structure refinement with SHELXL. Acta Cryst. Sect. C Struct. Chem. 2015, 71, 3-8. [CrossRef]

40. Dolomanov, O.V.; Bourhis, L.J.; Gildea, R.J.; Howard, J.A.K.; Puschmann, H. OLEX2: A complete structure solution, refinement and analysis program. J. Appl. Crystallogr. 2009, 42, 339-341. [CrossRef] 